\title{
Possibilities of surface waters monitoring at mining areas using UAV
}

\author{
Ewa Lisiecka $^{1}$, Barbara Motyka ${ }^{2}$, Zbigniew Motyka $^{1 *}{ }^{1}$, Lukasz Pierzchała $^{1}$, and Adam \\ Szade $^{1}$ \\ ${ }^{1}$ Główny Instytut Górnictwa, Katowice, Poland \\ ${ }^{2}$ Pekol, Siemianowice Śl., Poland
}

\begin{abstract}
The selected, remote measurement methods are discussed, useful for determining surface water properties using mobile unmanned aerial platforms (UAV). The possibilities of using this type of solutions in the scope of measuring spatial, physicochemical and biological parameters of both natural and anthropogenic water reservoirs, including flood polders, water-filled pits, settling tanks and mining sinks were analyzed. Methods of remote identification of the process of overgrowing this type of ecosystems with water and coastal plant formations have also been proposed.
\end{abstract}

Keywords: surface waters, monitoring, UAV

\section{Introduction}

Among the series of remote measurement methods, useful for determining surface water properties, such as satellite spectrometry methods, there have been opportunities to improve many of them through the use of mobile unmanned aerial platforms (UAV).

As part of the presented work, the possibilities were analyzed of using this type of solutions which can be widely used in the scope of measuring a number of spatial, physicochemical and biological parameters, both natural and anthropogenic water reservoirs, from pond and settler supervision to monitoring of dam reservoirs and watercourses. In addition, the possibility of remote inspection from a short distance of technical condition of hydrotechnical devices and analysis of the structure of the coastal zone.

\section{Scanning the spatial geometry of anthropogenic formations}

The UAV mobile unmanned platforms were used until now only for terrestrial measurements [1-2].

*Corresponding author: motyka@gig.eu 
In the first stage of works performed in Główny Instytut Górnictwa (Central Mining Institute), titled "Remote laser systems for determining geometrical parameters of anthropogenic forms of terrestrial surface formation", the methods have been proposed that can also be used to study such structures using laser scanners mounted on UAV platforms, as discussed in more details in previous studies [1-3]. 2D scanning is illustrated on the example of model from Fig. 1. Techniques for further numerical processing of similar fringe images do not differ from those presented in earlier studies [4-6]. However, much simpler effects are obtained with the use of 2D laser scanners that directly determine the distance from the scanning point to a series of points of each line shown in the drawing. Knowing the location of the UAV at any time, to create such a scan we can directly obtain a spatial image of the studied formation in the form of a cloud of points representing it.

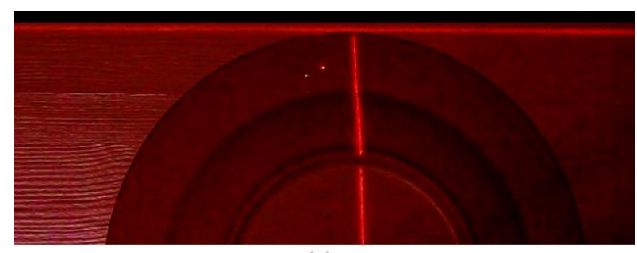

(a)

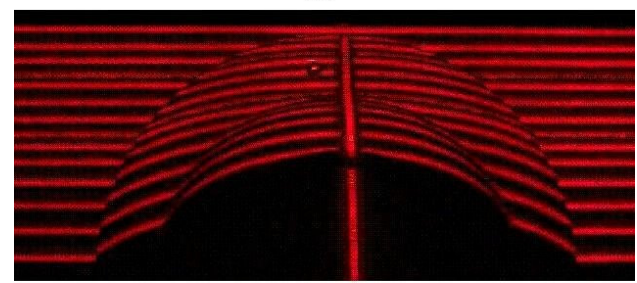

(b)

Fig. 1. Model of anthropogenic terrain formation (a) and 2D scan of the convex part of its spatial geometry for selected scan line 14 positions (b).

Earlier studies discussed the usefulness of laser 2D scanning methods, including remote mining shafts and geometry modeling of mining excavations. With regard to artificial water reservoirs, they will be equally effective for remote inspection from a short distances of technical condition of hydrotechnical devices (weirs, dams, dikes), and analysis of the structure of the embankment zone. While in the case of mine shafts and underground mine workings, the use of drones for laser scanning seems rather distant today and still a fantastic possibility, nothing precludes their use for external inspection of water devices, both with the use of $2 \mathrm{D}$ scanners, as well as the traditional photogrammetry from a very short distance.

\section{Phytoplankton and coastal plants}

Below, the methods of remote identification of the overgrowth process of this type of aquatic ecosystems with phytoplankton and coastal plant formations are also proposed (Fig. 2).

Satellite monitoring of flood areas, physicochemical parameters of smaller and larger water reservoirs, including the quality of their waters, are burdened with many limitations such as: spatial and spectral resolution of satellite scanners, suppression of radiation reflected from the surface of water through the atmosphere of the Earth, or observation angle. For this reason, spectrometric techniques for measuring the quality of water from close range (from a boat or from a bank of water reservoir) are developing, including chlorophyll-a 
content, turbidity and other physicochemical parameters such as PRI (Photochemical Reflectance Index), NDVI (Normalized Difference Vegetation Index) and others.

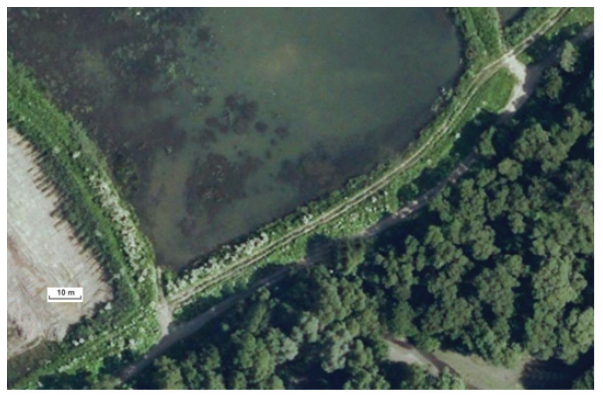

(a)

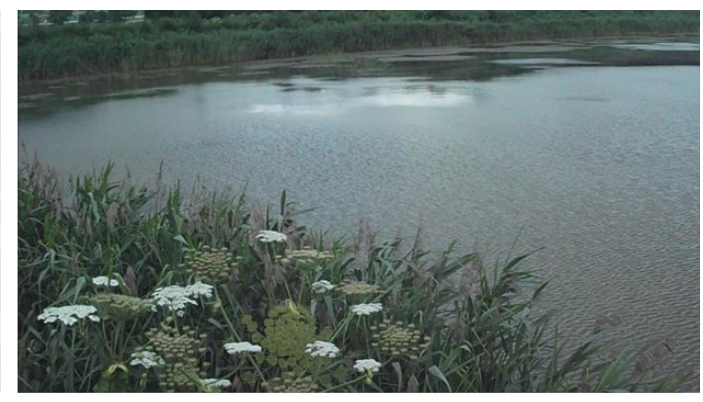

(b)

Fig. 2. Aerial photograph (a) and shore (b) of the artificial water reservoir in Łodygowice, covered with, among others, flowering formations of Heracleum $s p$.

Chlorophyll-a is the basic indicator of surface water quality, illustrating changes in the concentration of phytoplankton in water. Enrichment of aquatic ecosystems with biogenic substances (eutrophication process) results in excessive growth of lower vegetation (in particular algae and cyanobacteria). This process leads to a decline in biodiversity and a reduction in the potential of reservoirs to perform an economic and recreational function [78]. Assessment of the concentration of phytoplankton biomass using traditional methods requires direct sampling of water samples in the field and conducting costly and timeconsuming analytical methods.

Chlorophyll causes spectral changes in water. It is possible to determine it on the basis of spectral measurements.

The authors of the work carried out research work on the development of a chlorophyll-determination method in inland waters. For this purpose, the measurement of the spectral characteristics of solar radiation reflected from the water surface was used. The device recording the measurement data, in this case, was a monochromator spectrometer with a diffraction grating in the Czernego-Turner system and a photomultiplier as a detector.

Another method used to study the chlorophyll-a content in surface waters, especially in marine and ocean waters, may be the analysis of satellite data.

Inland waters are characterized by greater biological and optical complexity, which considerably hinders the application of spectral methods. Very often, the spectral characteristics of individual phytoplankton and suspension groups overlap, which forces the development of new algorithms that allow obtaining information for given surface water types [9]. The development of one universal calculation formula is therefore virtually impossible and requires in situ comparative testing. The application of the water quality monitoring method using photos from the Landsat system on lakes in Oklahoma allowed for a high correlation with water turbidity. However, there was no significant correlation of the chlorophyll-a content with individual spectral bands and their combinations [10]. High correlation coefficients $(0.944)$ between the actual chlorophyll-a concentration, calculated on the basis of spectral data, were obtained for a lake in New Zealand [11]. The SCyanoHABs system is an example of an effective implementation of the method for assessing the ecological status of lakes in the Mediterranean zone based on satellite images. Due to the low resolution of satellite images used in this method (MERIS system), this monitoring covers only the largest water reservoirs in Spain [12]. The limitations for methods using satellite images for surface water monitoring are also atmospheric conditions. 
The persistent cloudiness limits the possibility of satellite observation of the tank's surface. Conducting in situ observations allows for providing data with a higher resolution, without the disturbing influence of atmospheric conditions. To analyze the spectral characteristics of light reflected from the surface of water in situ, both specialized spectral cameras and relatively inexpensive digital cameras can be used [13]. The presence of chlorophyll-a is manifested by an increase in the spectral reflection, in the green and red radiation range, and increased absorption in the area of the blue spectrum. The analysis of information on the intensity of component colors from digital photography in graphic software allows the calculation of coefficients allowing the assessment of chlorophyll concentration in surface waters. Initial research using photographs taken with the help of a digital camera placed on a mobile unmanned flying platform indicates the high potential of this solution in the monitoring of inland surface waters [14]. The possibility of assessing the chlorophyll concentration on the basis of the analysis of the spectral characteristics of light reflected from the water surface is also confirmed by preliminary tests carried out with the aid of the presented measuring apparatus.

The UAV platforms prove to be particularly useful for the remote identification of overgrowth of water ecosystems with hardly accessible shoreline with phytoplankton, surface plants and coastal plant formations such as Heracleum sp., Petasites sp., Phragmites sp., Lemna sp., and many others [1,15] (Fig. 3 and Fig. 4).

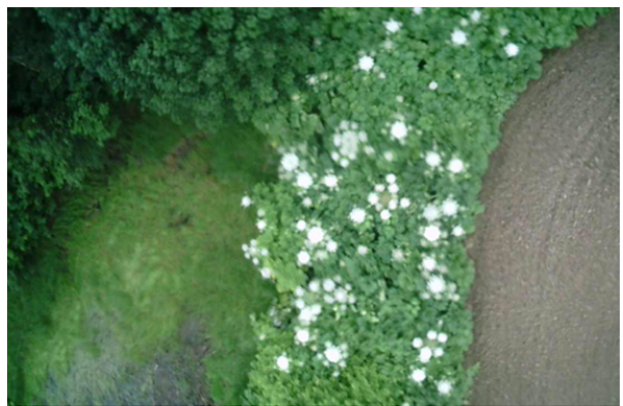

(a)

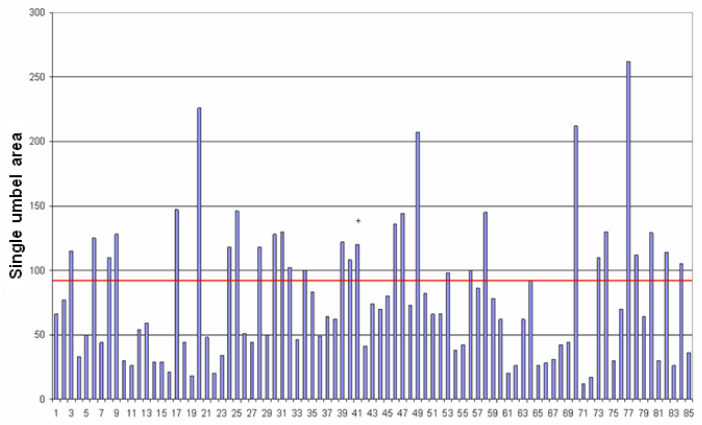

(c)

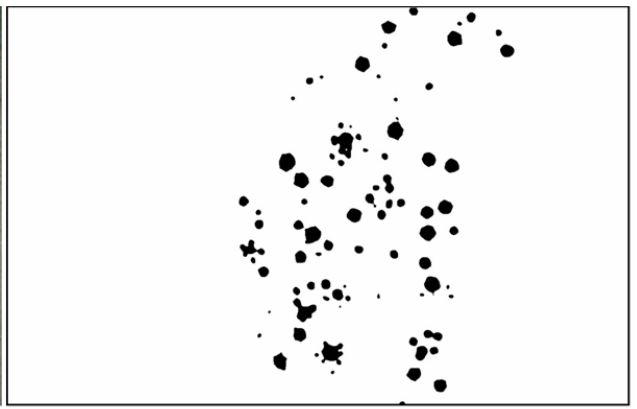

(b)

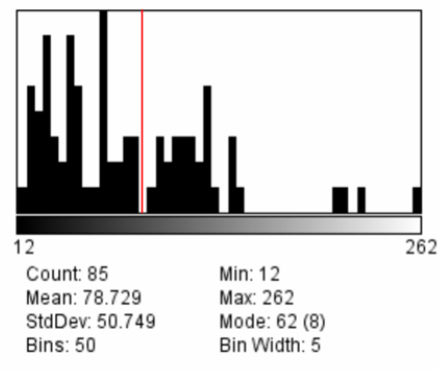

(d)

Fig. 3. Identification from the air of the overgrowth area of a small, anthropogenic water ecosystem with the water and coastal plant formations (a), especially from the Heracleum genus (b) allows to obtain a quantitative distribution of the canopy sizes of this plant (c) and (d). 

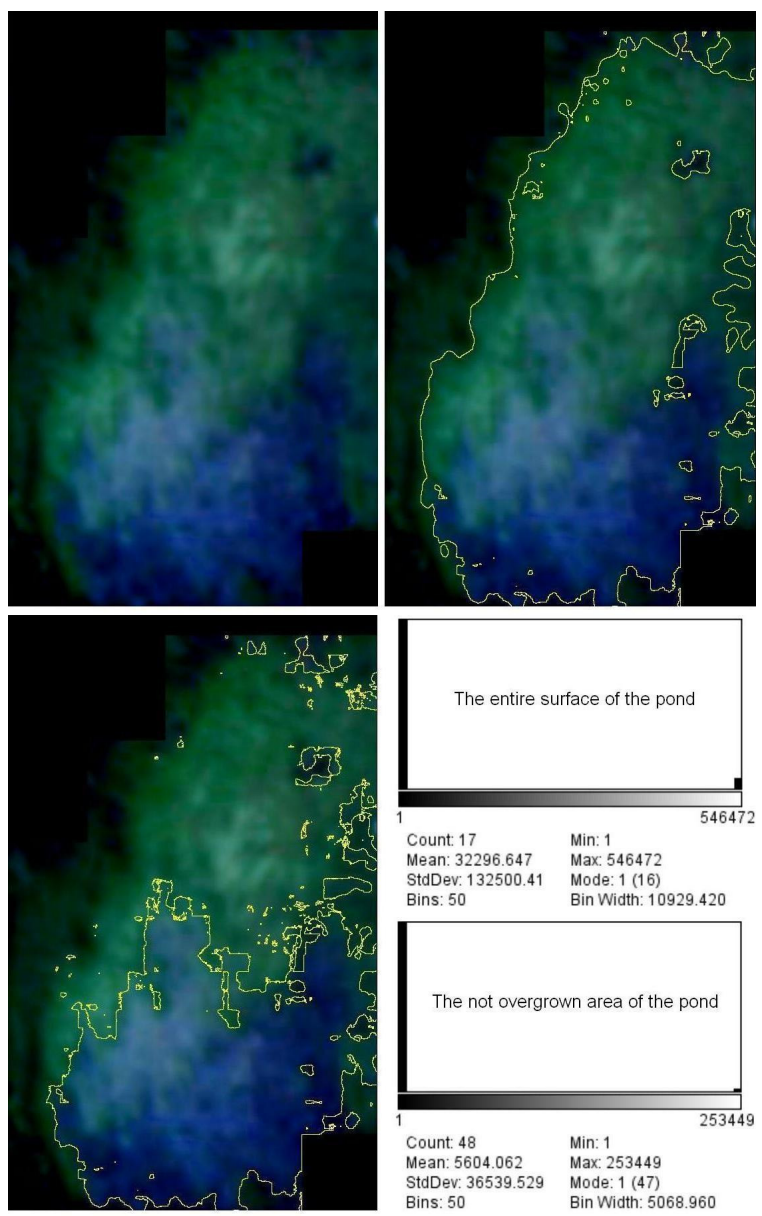

Fig. 4. Identification from the air of the overgrowth area of a small, anthropogenic water ecosystem with surface plants by image processing with the use of ImageJ software packet.

In the case of Heracleum sp., from the size distribution of umbel, it is possible, for example, to estimate the number of blooming individuals. In Figure 3, ImageJ software packet was applied to photograph (a) to extract with the use of picture processing negative images of white canopies only. Within the same packet a procedure was used counting number of black pixels for each of 85 black stain. The latter are presented in sequence (numbered according to the counting procedure advance) with the use of Excel (c). Their size distribution (d) was obtained with the use of another ImageJ procedure. The estimated visually number of approximately 31 blooming individuals remains in good accordance with the number of umbels with an area of nearly 90 pixels or more, indicated by red lines in diagrams (c) and (d).

The ImageJ software packet was also used to analyze the area of overgrown part of the adjacent pond which upper part is also visible at the left hand side of Heracleum sp. formation from Fig. 3a.

Its image colors were enhanced and details were blurred with the use of procedures of ImageJ to the form of a top left-hand picture from Fig. 4. Another procedures of this packet enabled to delineate areas of different colors corresponding visually overgrown part of the pond only (the bottom left-hand picture from Fig. 4) and its entire area (the top right-hand picture from Fig. 4). The both areas were calculated as a number of pixels (253449 and 
546472) contained within them with the use of procedure of ImageJ and the results were presented at the bottom right-hand side diagrams of Fig. 4. The ratio of the area not overgrown to the entire surface of the pond from Fig. 4 is approximately 0.46 .

\section{Surface water pollution}

In the first stage of works performed in GIG in 2016, titled "Monitoring of selected parameters of low emission and location of surface water pollution with the use of drones", a measurement platform for selected low emission parameters was set up for drones in the form of a hybrid optoelectronic meter for $\mathrm{CO}, \mathrm{CO} 2$ and low emission dust fractions. The use of drone as a mobile carrier for the measuring platform plays a key role here. Combustion (co-firing with coal) of plastics (PVC, polyurethanes, PET) results in the formation of very toxic compounds, such as hydrogen chloride, carcinogenic dioxins and furans, formaldehyde and others, which may then flow from the air to surface waters as a result of precipitation. Therefore, it is important to determine such components already in the air in the vicinity of or over open water reservoirs. For example, the possibility of measuring the distinctive characteristic component, such as $\mathrm{HCl}$, as well as the possibility of collecting gas samples for further analytical laboratory tests based on procedures based on current regulations and standards, may be important here. The device for remote laser determination from the UAV deck of physical-geometrical parameters of anthropogenic forms of terrain surface formation, developed in GIG, may also be useful for mapping water reservoirs and air pollution above them [3]. The second stage of the project involves the construction of drone equipment with an infrared and spectral camera for the location of discharge of pollutants into waters, as well as the extension of applications based on GIS.

\section{Summary}

The possibilities of using photogrammetry with the use of UAV for mapping the coastal zone of specific plant cover, as well as overgrowing of open water reservoirs were shown.

Another area of application for drones may be the construction of measuring platforms that will allow the assessment of surface water quality and the identification of pollution discharge points. The next stage in the development of remote methods for measuring surface water quality may be the placement of measurement devices recording spectral reflection from the water surface, in interesting spectral ranges or for selected wavelengths, on a mobile unmanned aerial platform. Such a solution will allow adjusting the parameters of the remote sensing device to the conditions in which the measurements are carried out and to carry out measurements in situ directly over a specific water reservoir.

\section{References}

1. Motyka Z., JCEEA, XXXIV, 64, 2/II/17 (2017).

2. Motyka Z., In: Innovative development of the mining industry (Kryvyi Rih National University, Kryvyi Rih, 2016).

3. Motyka Z., P.417785, BUP 4 (2017).

4. Motyka Z., Proc. SPIE, 5229, 10 (2003).

5. Motyka Z., Wiadomości Górnicze 5 (2005).

6. Motyka Z., Passia H., AIP Conf. Proc., 1457/1 (2012).

7. Scheffer, M.Ch.H., Ecology of Shallow Lakes (London, 1998). 
8. Pierzchała, Ł., Sierka, E., Trząski, L., Bondaruk, J., Czuber, B., AEER 14, 1 (2016).

9. Kruk, M., Rychter, A., Mroz, M., Zalew Wiślany - środowisko przyrodnicze oraz nowoczesne metody jego badania na przykładzie projektu Visla (PWSZ, Elbląg, 2011).

10. Barrett, D. Clay; Frazier, Amy E., Water, 8.6, 257 (2016).

11. Allan, M.G.; Hamilton, D.P.; Hicks, B.J.; Brabyn, L., Int. J. Remote Sens. 32 (2011).

12. Gómez, J. A. D., Alonso, C. A., García, A. A., EMA, 181, 1-4, (2011).

13. Goddijn-Murphy, L., Dailloux, D., White, M., Bowers, D., Sensors, 9 , 7 (2009).

14. Cândido, A. K. A. A., Paranhos Filho, A. C., Haupenthal, M. R., da Silva, N. M., de Sousa Correa, J., \& Ribeiro, M. L., WASP, 227, 7 (2016).

15. Motyka B., Motyka Z., In: Zwalczanie inwazyjnych gatunków roślin obcego pochodzenia - dobre i złe doświadczenia (Stowarzyszenie „Człowiek i Przyroda”, Krzywe, 2015). 